\title{
IoT and Smart Cities - the Foundation for an Intelligent Life Style
}

\author{
Marian STOICA, Bogdan GHILIC-MICU, Marinela MIRCEA, Cristian USCATU \\ Bucharest University of Economic Studies, Romania \\ marians@ase.ro,ghilic@ase.ro,mmircea@ase.ro, cristiu@ase.ro
}

Population migration towards urban agglomerations, whether inside or around them, is a socio-economic process that happens in most if not all countries in the world. (situation seriously accentuated as an effect of the pandemic of the last two years). This increasing trend leads to a series of difficulties for the urban environments, yielding from increase in occupied space and number of inhabitants, demand for transportation, telecommunication, public services and infrastructure, increase of criminality and pollution. In time, these difficulties can lead to decrease in cities' ability to manage the inhabiting population and services for them. Increase of population and need for security and privacy, ever pressing need to protect the environment and diversification of demands regarding quality of life are only a few of the reasons that justify the need to adopt a more intelligent life style. The technological and conceptual is supported by the smart city paradigm merged with the internet of things. In this paper we aim to explore the main features of smart cities, to present their advantages and disadvantages in the global economic context and to present the extent to which the ecosystem represented by IoT and smart cities is a stimulator for a smart life style.

Keywords: Smart City, Internet of Things, Intelligent Life Style, Quality of Life, Public Services, Privacy, Security.

DOI: $10.24818 /$ issn14531305/25.4.2021.02

\section{Introduction}

According to World bank studies [1], currently cities host over $55 \%$ of the world population. These statistics indicate a stable evolution of urbanization over time, thus creating a constant pressure on all aspects of urban life. In Romania, in 2020 the urban population represented $54.194 \%$ of total population and at July $1^{\text {st }}, 2021$ it jumped to $56.30 \%$ [2]. Cities are also responsible for two thirds of the world energy consumption and over $70 \%$ of $\mathrm{CO}_{2}$ emissions. The high number of inhabitants is a continuous challenge for urban government, manifesting itself in the management of resources, traffic, environment, security and public services.

One solution for solving all these aspects could be the large-scale implementation of smart city paradigm. In other words, we mean cities that have the ability to monitor the status and functioning of critical infrastructure in order to optimize the resource usage, plan the maintenance and prevention activities, monitor the security status etc. with the end goal of maximizing the quality of services provided to the citizens. A smart city is a framework consisting mainly of information and communication technologies (ICT) used to develop, implement and promote sustainable development practices designed to meet the increasing challenges of urbanization [3].

All these challenges require an innovative approach, as they are the starting point for designing a better living standard that puts comfort, accessibility and efficiency above all else. The concept of smart living in a smart city provides a viable solution meant to promote an efficient consumption of energy, safer communities, digital infrastructure, increased involvement of citizens and administration, a reduced carbon print, better quality public services and new economic development opportunities.

All these are accomplished by integrating advanced technologies into daily life (like ICT, Big Data, efficient decision algorithms) and by interconnecting smart devices and gadgets that combine into a smart ecosystem: internet of Things (IoT).

A smart city isn't restricted only to use of mentioned technologies for a better usage of 
resources and lower emissions. Sustainability must be promoted through smarter urban transport networks, better water distribution networks and waste removal systems, more efficient lighting and building heating and reduction in operational costs of infrastructure. In an ideal situation, a smart life style represents one of the six indicators that may be invoked to characterize a smart city. The other five indicators are: smart citizens, smart mobility, smart economy and smart govern- ing/administration [4]. They do not act independently, but rather influence each other contributing together to the improved quality of life (figure 1).

The interest for smart cities is continuously growing, estimation indicating that the revenue generated by global smart city companies from 2020 to 2025 will reach over 350 bln. USD, from the current amount of 129 bln. USD. In 2021, the best developed segment of smart cities is the smart mobility (27.7 bln. USD) [5].

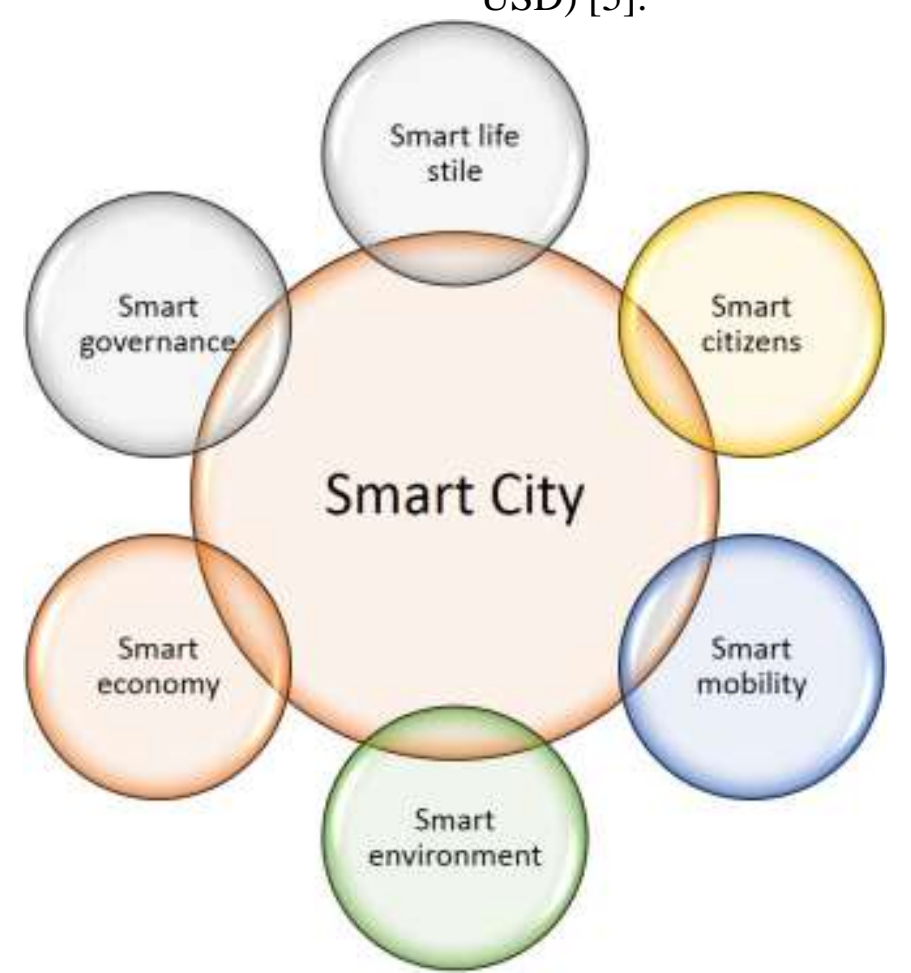

Fig. 1. Six key elements of urban development in smart cities (after [4])

Still, there are challenges regarding the sustainability of an intelligent life style, generated from the necessity for continuous innovation. Also, such challenges arise from the need to satisfy ever diversifying requirements of the population and to meet the most pressing needs in an efficient manner. The high amount of capital needed can also be considered a factor in the development of smart cities since it is usually a barrier on the path to success. Additionally, the adaptation to new technologies and gaining the trust of users may be difficult without specific regulations, unanimously accepted and well understood by all involved actors.
2. Forbes top 10 smart cities - advantages and disadvantages for each

In the logic of our scientific endeavor, we will review the top of 10 most popular smart cities in the world. We have chosen the list compiled by Forbes in 2020 through IESE Business School's Center for Globalization and Strategy [6]. The ranking criteria used by Forbes is an annual smart city index that measures the development of 174 cities worldwide from the perspective of nine criteria. These criteria were deemed essential for a really smart and sustainable city. They are: economy, environment, human resource, international projec- 
tion, mobility and transportation, social cohesion, technology and urban planning (figure 2).

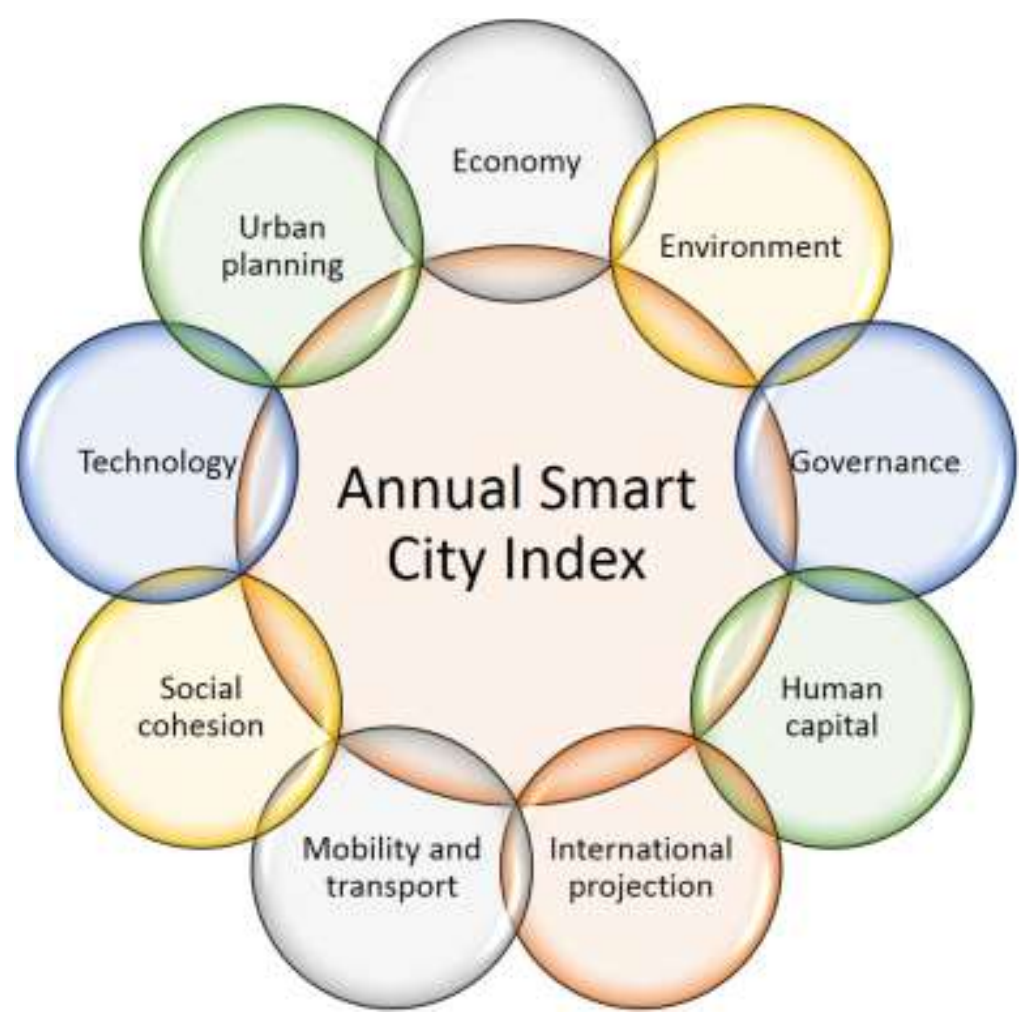

Fig. 2. Components of annual smart city index (after [6])

\section{London}

London, that hosts more startups and programmers than almost any other city in the world, always had a good position in this top, acquiring the first position in 2017 and keep it since then. This performance comes from a good position on almost all criteria: first on human resource and international projection, second on urban governing and planning, and in top 10 for mobility, transportation and technology. Its worst indicators are social cohesion, where it sits on 64, and environment, where it takes position 35 .

\section{New York}

New York is second in the general standings. It comes mainly from the economy indicator (where 9 of top 10 cities are from USA), urbanization ( 6 of top 10 cities come from USA) and mobility and transportation. The weakest point is social cohesion, where it sits very close to the bottom, on position 151 from 174 analyzed cities.

Paris
Tanking the third position in general standings is Paris, as one of the main tourist destinations in the world. It has a very strong position on international projection (second best indicator). Also, it has a good mobility and transportation (second best) and human resource (position 6). These indicators reflect the ability of a city to attract, cultivate and develop talent. The weakest standings are on social cohesion (position 74) and environment (position 48).

\section{$>$ Tokyo}

Tokyo is the best placed city from Asia-Pacific region, fourth in the general standings. The Japanese metropolis is strong regarding the economy (position 3), environment (position 6) and human resource (position 9). It doesn't do well on social cohesion (position 74 together with Paris). From a city with considerable technological influence on the world stage, Tokyo is evolving its smart city concept towards the social dimension. New initiatives were adopted to tackle the country's aging population problem. 
Reykjavik

Reykjavik takes the fifth place, while being the best regarding the environment standings. This comes from the use of $100 \%$ regenerable energy sources (hydroelectric and geothermal). Thus, the city is the world leader in energetic sustainability and smart solutions. Another strong point is the social cohesion (position 14) while the weak points are the urban planning (position 125) and economy (position 86).

\section{$>$ Copenhagen}

The capital of Denmark takes the sixth position in general standings. Is does very well in environment (second best) due to low pollution and contamination. Also, urban governing is well appreciated (position 7). The weak point is urban planning (position 81).

\section{$>$ Berlin}

Berlin is the best placed German city, seventh in the general standings. It does very well in mobility and transportation (position 4), human resource (position 5) and international projection (position 9). On the not so good list are economy (position 59) and environment (position 42).

\section{$>$ Amsterdam}

Amsterdam takes the eighth place, with good performance in international projection (position 5), reflecting its status of tourist attraction, and mobility and transportation (position 11). Its weakest standing is social cohesion (position 50).

\section{$>$ Singapore}

Singapore is the ninth city in this top, but the first one that launched a driverless taxi service, with plans to introduce driverless busses in 2022. It is not surprising that this city is second best on technology and third best in international projection, whole the environment indicator places it on position 7. Mobility and transportation (position 55) reduced its general standing.

\section{$>$ Hong Kong}

Hong Kong is one of the most influential cities in South-East Asia and the tenth in this top. It is a very important port and global financial hub, with the technology indicator placing it first in the world. The Hong Kong Smart City Blueprint initiative attempts to use innovation and technology to approach challenges like city management and quality of life. The international projection indicator places Hong Kong on position 4. Social and political imbalances drag the social cohesion indicator to position 111.

The continuous development of smart city related technologies (not limited to the 9 indicators invoked in the Forbes top), indispensable for a smart living, as well as improved access to them means that IoT will continue to model the human lives in the years to come. As the adoption of smart technologies increases and new innovations emerge, more and more persons will experiment with it to benefit from saving time, money and energy, ease of use or increase daily comfort.

\section{Smart city paradigm in Romania and Europe}

In October 2020, the European Commission launched an initiative to implement smart city solutions under the name Smart City Marketplace. It was created by fusing together, in a single platform two former projects: European Innovation Partnership in Smart Cities and Communities (EIP-SCC) and Smart City Information System (SCIS). Additionally, this initiative is a major promise that aims to bring together cities, industries, SMEs, investors, researchers and other actors of smart cities. The goals of this initiative are: improve the quality of life for all citizens, increase the competitivity of European cities and industries as well as reaching the energy and climate targets [7].

The Smart City Marketplace initiative may be perceived as a consequence of December 2019 action, when the European Commission presented to the European Parliament the document entitled The European Green Deal Europe's new growth strategy.

On national level, the smart city idea is not new. Following numerous local initiatives (Cluj-Napoca, Timișoara, Arad, Craiova, Alba-Iulia, Bucharest, Ploiești etc.) it became a specific goal (objective nr 11) for the National Sustainable Development Strategy of Romania (SNDDR). The strategy was adopted by the Romanian Government on November 
$9^{\text {th }}, 2018$, through HG 877/2018 [8]. According to SNDDR, "A smart and durable city is an innovative city which, through use of information and communications technology, data collected from devices used to provide service, smart design of urban development - under the coordination of a smart administration - reaches the necessary synergy to improve the quality of life, efficiency of urban operations and services, as well as competitivity, covering the needs of current and future generations in regards to economic, social and environmental aspects".

The definition and objectives of SNDDR are wonderful and daring for the Romanian 2030 horizon, maybe even for 2050 or 2100, for a simple reason. Although Romania is a wonderful country from geographic point of view, with all types of landscapes and naturally rich, the population cannot seem to be able to get past some old habits and mentalities. In spite of official declarations, the poor state of the public education system does not seem to be able to overcome mentalities and push the country into the new social and technological era, at least not fast enough to keep pace with the rest of the world. The ambitious SNDDR 2030 target seems more like a mirage or a castle built on cardboard foundations.

\section{IoT ecosystem and smart cities - stimulus for an intelligent life style}

Smart cities use a variety of software, user interfaces and communication networks, along IoT, to provide the public with high standard technological solutions. Of these, IoT is the most important, being a network of connected devices that communicate and exchange data. There is a large variety of devices include in this network, from vehicles to household appliances and various sensors. Data is collected and stored in cloud or on servers to be later used to improve the efficiency of public and private activities, to improve the quality of citizens' lives and bring economic benefits.

Many IoT devices use edge computing, allowing them to send only the most relevant and important data into the communication network. Additionally, they implement a security system that protects, monitors and controls the transmission of data through the smart city network and prevents unauthorized access to the IoT network of the city's data platform. Beside IoT solutions, smart cities use other technologies, like: Application Programming Interfaces (APIs), Artificial Intelligence (AI), Could Computing Services, Dashboards, Machine Learning, Machine-to-Machine Communications and Mesh Networks. Even more, in order to make a smart city hum, three sides must interoperate. Figure 3 shows a city smartness structure in the vision of McKinsey Global Institute [9]. The first side is the technological base, including a critical mass of smartphones and sensors connected through high-speed communication networks. Second side is represented by specific applications. Translating the raw data into alerts, perspectives and actions requires adequate instruments and this is where technology providers and application developers come in. The third side is the use of data by cities, companies and the public. Many applications are successful only if they are adopted on large scale and manage to change behaviors or habits. They encourage people to use public transportation outside work hours, change routes to optimize the whole transport process (see also [10]), consume less energy and water, change the time of day for some actions and reduce the pressure on public health systems through preventive selfcare. 


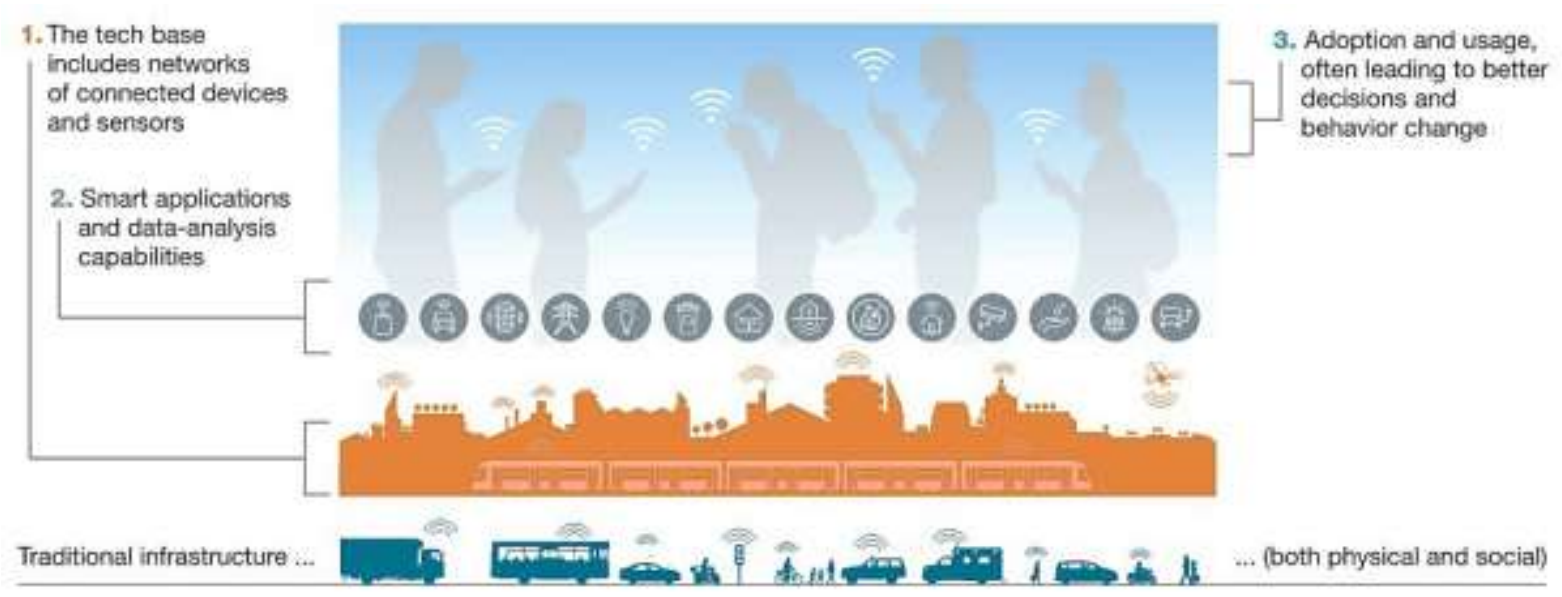

Fig. 3. Structure of a city's smartness (after [9])

The most recent study of the Organization for Economic Co-operation and Development OECD - draws the conclusion that by 2050 the world population will increase to 9 billion persons and $70 \%$ of them will live in urban centers. This implies the need to optimize the inner working of cities and maximize the agility of city management. For this reason, more and more cities look to the Smart City. Although some of the first cities to adopt this direction, like Tokyo, Singapore or New York, implement global initiatives, most progress happens in environments specific to each city. According to the most recent Statista report, investments in this sector totaled 124 million USD last year. Estimations indicate that by 2030 the size of smart city market worldwide will increase to $1380 \mathrm{bln}$. USD, from $393 \mathrm{bln}$. in 2019 [11].

\section{Conclusion and research directions}

In an ideal situation, smart cities put data and digital technologies in the service of better decisions for improving the quality of life. For smart cities to be successful, beside individuals, housing, trade and traditional urban infrastructure, there are four other important elements required to support the development: ubiquitous wireless connectivity, open data, guaranteed security and flexible site monetization schemes.

The smart life style is a trend that involves improved standards in several aspects of daily life, from household to workplace and people transportation across the city. It also involves healthcare, social and digital inclusion and safety. Therefore, as an emerging sector of economic and social life, smart living contributes to an increase in citizens' living standard, whether we look to younger generation or seniors, due to medical progress in treating and saving patients, autonomous devices and security which make life significantly easier and devices that protect the environment.

Any step forward must be undertaken in the context of real social cohesion, on an appreciable level of education and a realistic mentality that goes beyond the Horatian expression, unfortunately turned into aphorism: "Carpe diem, quam minimum credula postero". These are the premises of a very serious future research direction.

\section{References}

[1] World Bank, "Urban population (\% of total population). United Nations Population Division. World Urbanization Prospects: 2018 Revision.," World Bank, 2018. [Online]. Available: https://data.worldbank.org/indicator/SP.URB .TOTL.IN.ZS. [Accessed 1010 2021].

[2] Institutul Naţional de Statistică - INS România, "Populaţia după domiciliu la 1 iulie 2021," 29 October 2021. [Online]. Available: https://insse.ro/cms/ro/content/popula\%C5\% A3ia-dup\%C4\%83-domiciliu-la-1-iulie2021. [Accessed 10 December 2021].

[3] Thales Group, "Secure, sustainable smart cities and the IoT," Thales Group, 2020. [Online]. Available: https://www.thalesgroup.com/en/markets/dig 
ital-identity-and-security/iot/inspired/smartcities. [Accessed 1110 2021].

[4] Vienna University of Technology, "europeansmartcities 4.0 (2015)," 2015. [Online]. Available: http://smartcities.eu/?cid=2\&ver=4. [Accessed 2021].

[5] A. Holst, "Smart Cities - Statistics \& Facts," 25 May 2021. [Online]. Available: https://www.statista.com/topics/4448/smartcity/\#dossierKeyfigures. [Accessed November 2021].

[6] Forbes, "The Smartest Cities: Top Ten," IESE Business School's Center for Globalization and Strategy, 2020. [Online]. Available:

https://www.forbes.com/sites/iese/2020/07/0

8/these-are-the-10-smartest-cities-in-theworld-for-2020/?sh=c02eaa12af26.

[Accessed 1 December 2021].

[7] European Commision, "Piața orașelor inteligente," European Commision, 01 October 2020. [Online]. Available: https://smart-citiesmarketplace.ec.europa.eu/?lang=ro. [Accessed 17 June 2021].
[8] Guvernul României, Strategia națională pentru dezvoltarea durabilă a României 2030, București: Paidea, 2018.

[9] McKinsey Global Institute, "Smart cities: Digital solutions for a more livable future," McKinsey Global Institute, 05 June 2018. [Online]. Available: https://www.mckinsey.com/businessfunctions/operations/our-insights/smartcities-digital-solutions-for-a-more-livablefuture. [Accessed 10 November 2021]. [10] M. Stoica, B. Ghilic-Micu and M. Mircea, "The Telework Paradigm in the IoE Ecosystem - A Model for the Teleworker Residence Choice in Context of Digital Economy and Society," Economic Computation and Economic Cybernetics Studies and Research, vol. 55, no. 3, pp. 263278, 2021.

[11] Statista, "Smart cities market revenues worldwide 2019-2030," Statista, 17 November 2021. [Online]. Available: https://www.statista.com/statistics/1256262/ worldwide-smart-city-market-revenues/. [Accessed 10 December 2021].

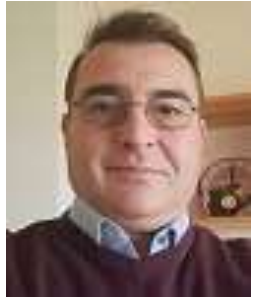

0003-2852-9224]

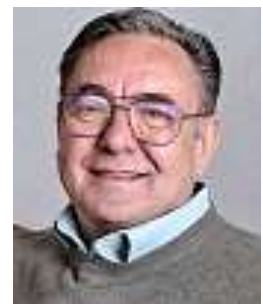

Bogdan GHILIC-MICU received his degree on Informatics in Economy from the Bucharest University of Economic Studies in 1984 and his doctoral degree in economics in 1996. Between 1984 and 1990 he worked in Computer Technology Institute from Bucharest as a researcher. Since 1990 he teaches in Academy of Economic Studies from Bucharest, at Informatics in Economy Department. His research activity, started in 1984 includes many themes, like computers programming, software integration and hardware testing. The main domain of his last research activity is the new economy - digital economy in information and knowledge society, computer programming. [https://orcid.org/0000-0003-3038-1302] 


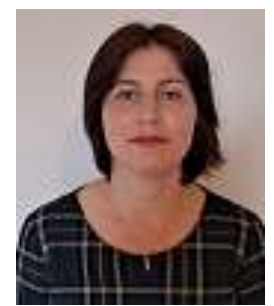

Marinela MIRCEA received her degree on Informatics in Economy from the Bucharest University of Economic Studies in 2003 and his doctoral degree in economics in 2009. Since 2003 she is teaching in Academy of Economic Studies from Bucharest, at Informatics and Cybernetics Economy Department. Her work focuses on the programming, information system, business management and Business Intelligence, IoT and education technologies. In February 2009, she finished the doctoral stage, and her PhD thesis has the title Business management in digital economy. [https://orcid.org/0000-0003-1870-6020]

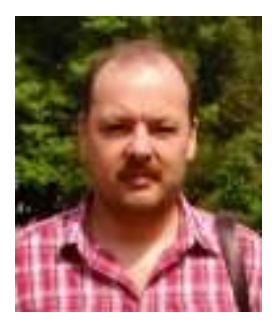

Cristian USCATU received his degree on Informatics in Economy from the Bucharest University of Economic Studies in 1997 and his doctoral degree in economics in 2007. In the present he is Associated Professor, $\mathrm{PhD}$, currently working with the Bucharest University of Economic Studies, Faculty of Cybernetics, Statistics and Informatics, Department of Informatics and Cybernetics in Economy. Competence areas: computer programming, data structures, evolutionary algorithms, e-voting, emergent information and communications technologies. [https://scholar.google.com/citations?hl=ro\&user=BC-YFMAAAAJ\&view_op=list_works\&sortby=pubdate] 